\title{
PREDICTING WATER FLUCTUATION IN COASTAL ENCLOSED LAGOON USING INTEGRATED TWO-DIMENSIONAL SURFACE AND SUBSURFACE WATER MODEL
}

\author{
Jun Kong $^{12}$ Zhiyao Song ${ }^{3}$ and Zhuo Zhang ${ }^{2}$
}

\begin{abstract}
Based on integrated vertically averaged free-surface and subsurface model, detailed analysis was focused on the water fluctuation in the enclosed lagoon caused by tidal movement. It is shown that when porosity of sand is increased, the water storage capacity in sand beach will be increased and the amplitude of vibration in the lagoon will be decreased. On the contrary, when permeability coefficient is increased, the amplitude in lagoon will be increased, and the phenomena of phase lag will be reduced either. Research reveals there is periodical water exchange between lagoon and out sea on the two sides of the sand beach. The procedure of water going into the lagoon happens differently from that of water coming out from lagoon. Because there is over-height in the lagoon, the time of water transporting from the lagoon to the out sea is longer than the reverse procedure and the maximum of water flux in the first procedure is shorter than the later. Further more the water moving from lagoon to open sea usually happens in the initial stage of flood and later stage of ebb, while the reverse procedure happens in the later stage of flood and initial stage of ebb.
\end{abstract}

Keywords: extended shallow water equation; integrated model; water fluctuation in lagoon; flux exchange

\section{Introduction}

According to survey, more than $13 \%$ the coastal zone consist of sand beach and lagoon. Lagoon, the ecotone between land and sea, is an important ecosystem to mankind. Some lagoons are connected with the sea via an explicit tidal inlet, while others are not connected with the sea directly but surrounded by permeable sand beaches. Due to such a direct or indirect connection with dynamic tidal water, the water in lagoon fluctuates periodically. Although the fluctuation is weak, the long-existed water exchange procedure will leads to the environment issue that the polluted water can moves not only from open sea to lagoon but in the reverse direction. So it is meaningful to study hydrodynamic problem of interaction between lagoon and adjacent waters to discover its special movement mechanism. As regards to the Field data is limited, numerical model as a modern method can be accepted in such research (Panday et al.,2004 ; Leticia et al., 2008).

\section{Governing equations}

In the coastal area, the research domain in plan is much larger than that in vertical direction. Two dimensional shallow equations are usually accepted in simulation such dynamic system (Walters et al, 2009). Considering in such area, the exchange between surface and subsurface are common in the method of plan advection. The depth-integrated two-dimensional equations can be set up:

$$
\begin{aligned}
& \frac{\partial \bar{u}_{i}}{\partial t}+\frac{\partial \bar{u}_{i} \bar{u}_{j}}{\partial x_{i}}=-g \frac{\partial \zeta}{\partial x_{i}}+\frac{\partial}{\partial x_{i}}\left(v_{i} \frac{\partial \bar{u}}{\partial x_{i}}\right)+\frac{\partial}{\partial x_{j}}\left(v_{j} \frac{\partial \bar{u}}{\partial x_{j}}\right)-g \frac{n^{2} \sqrt{\bar{u}_{i}^{2}+\bar{u}_{j}^{2}}}{h^{4 / 3}} u_{i}-\frac{g}{K} \bar{u}_{i} \\
& n_{e} \frac{\partial \zeta}{\partial t}+\nabla(h u)=q
\end{aligned}
$$

These equations are a new kind of extended shallow water equations where $\zeta$ is the elevation(L) in surface flow or water head in subsurface water, $u_{i}$ is velocity $\left(\mathrm{LT}^{-1}\right), n$ is manning coefficient, $q$ is source or sin. $K$ is hydraulic conductivity $\left(\mathrm{LT}^{-1}\right), n_{e}$ is effective porosity. In this paper, the formulas are named $\boldsymbol{E S W E}$.

\footnotetext{
${ }^{1}$ Nanjing Hydraulic Research Institute, 223 Guangzhou Road, Nanjing, Jiangsu,210029,China

${ }^{2}$ Hohai University, 1 Xikang Road, Nanjing, Jiangsu, 210098, China

${ }^{3}$ Key Laboratory of Virtual Geographic Environment, Nanjing Normal University, 1 Wenyuan Road, ,Nanjing, Jiangsu, 210038, China
} 
On the right of the momentum equation there are two kinds of resistance. The former reflects the resistance caused by the bed bottom while the later is the resistance when water moves in the porous medium. When $n_{e}$ is set to unit, the later resistance is zero (Mcdougal,1993; Huang,2003), then the new kind of extended equation can return to the traditional shallow water equations. The former resistance is much smaller than the later, so the ESWE will not influence its usage in subsurface flow. The equations make it possible to build an integrated model suitable in surface and subsurface flow. Different from the work of Yuan (2008) and Kong (2010), in present model only one layer and one set of equations need to be considered for simplicity. So it is feasible to revise the existing surface flow model. Besides this, by considering the quadratic term, the non-linear action of ground water can be simulated with large permeability. Based on the extended equation, the model built in this paper is not a coupled model but an integrated model.

Semi implicit Eulerian-Lagrangian finite volume/finite difference method is recommended (Casulli, 1998). The finite volume method used on the continuity equation ensures the mass conservation. Implicit algorithm is used on the friction term of the momentum equation, and the explicit scheme is employed on other terms to insure the stability and efficiency. Special treatments should to be made on the friction term of the momentum equation. Special judgment need to be considered to deal with the dry and wet problem. In flood process, only the surface water movement will be considered and porosity $n_{e}$ is set to 1 ; in drying process, only the subsurface water movement will be considered and porosity is set to the actual effective porosity of aquifer. The modeled domain was only one layer and the framework is very like the work of Liang (2007).

\section{Modelling}

Ebrahimi's case was a physical model based on the tidal and geometric feather of West Fleet Lagoon in England (Ebrahimi et al., 2007). In the experiment, the permeable sand beach separated the lagoon from the tidal area. The lagoon was on the left of the sand beach, shown in Fig. 1 and on the right is the water body represent open area. An impermeable wall was placed on the left end of the domain, so water can only pass in and out through the sand beach. When there is water fluctuation at the right of the sand beach, there was also water fluctuation in the lagoon left to the sand beach, indicating there was water exchange between two sides in the sand beach. Because the sediment choose in the experiment is relative coarse, there is no obvious seepage face.

In the experiment, non-cohesive sand was used to build the sand beach, with particle size of $1 \mathrm{~mm}$, conductivity coefficient of $1 \mathrm{~cm} / \mathrm{s}$, porosity of 0.3 ; the water depth was $214 \mathrm{~mm}$ under the average level, tidal amplitude was $60 \mathrm{~mm}$ in open sea with period of 355s, the initial water head at the two sides were $60 \mathrm{~mm}$. Elevation was measured at point A (in the lagoon) and B(in open sea).

Comparisons between coupled model (Kong et al, 2010) and present integrated model show that the numerical simulation precision is also satisfying. Present model can also predict the water fluctuation well, shown in Fig.2 3. Meanwhile this model tracked exactly the oscillation process in lagoon and reflected clearly the moving boundary phenomena, shown in Fig.4

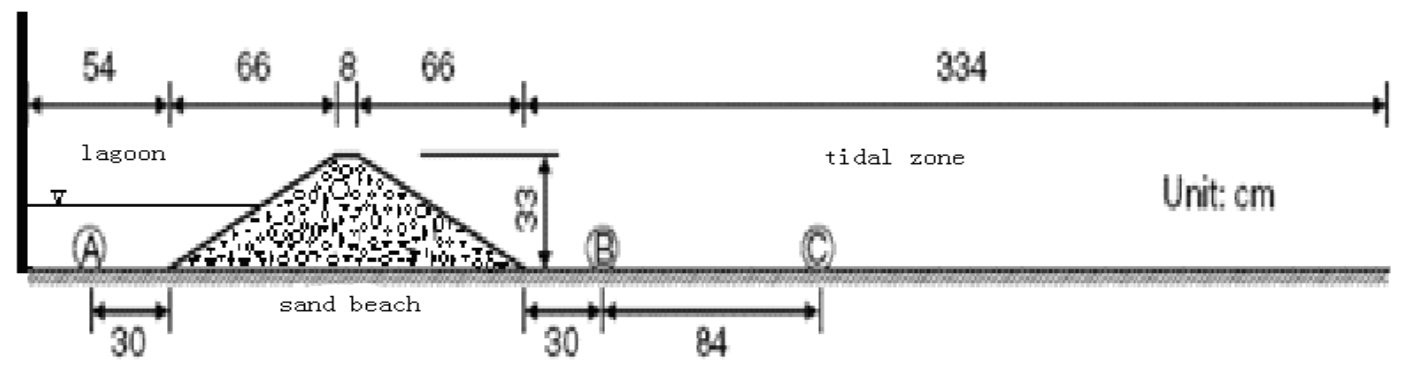

Figure 1. Physical model 


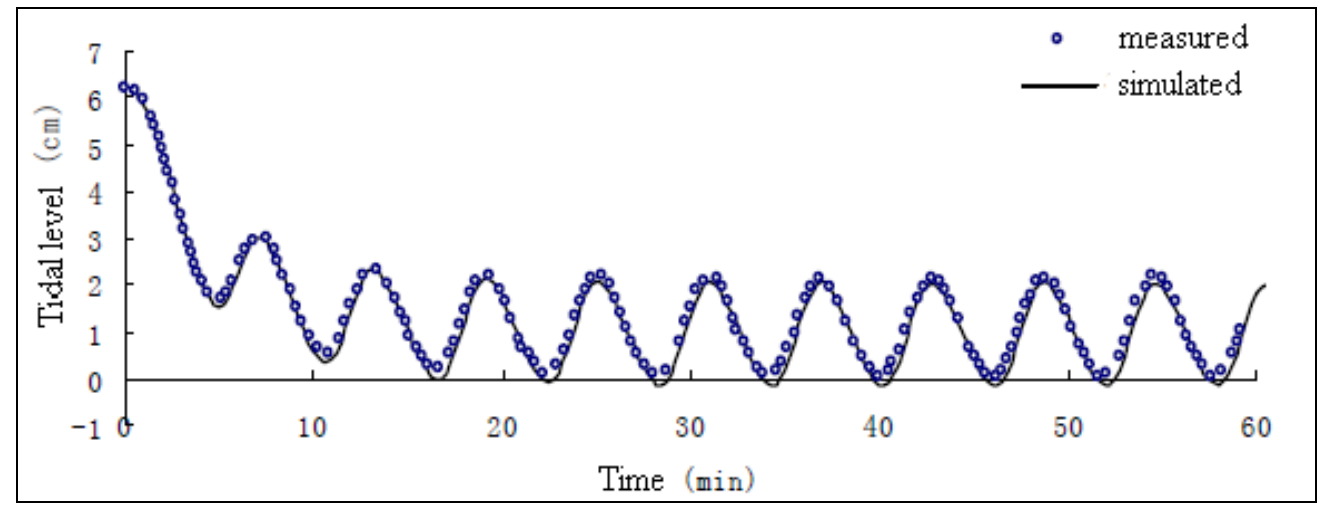

Figure 2. Verification of tidal level at point $A$

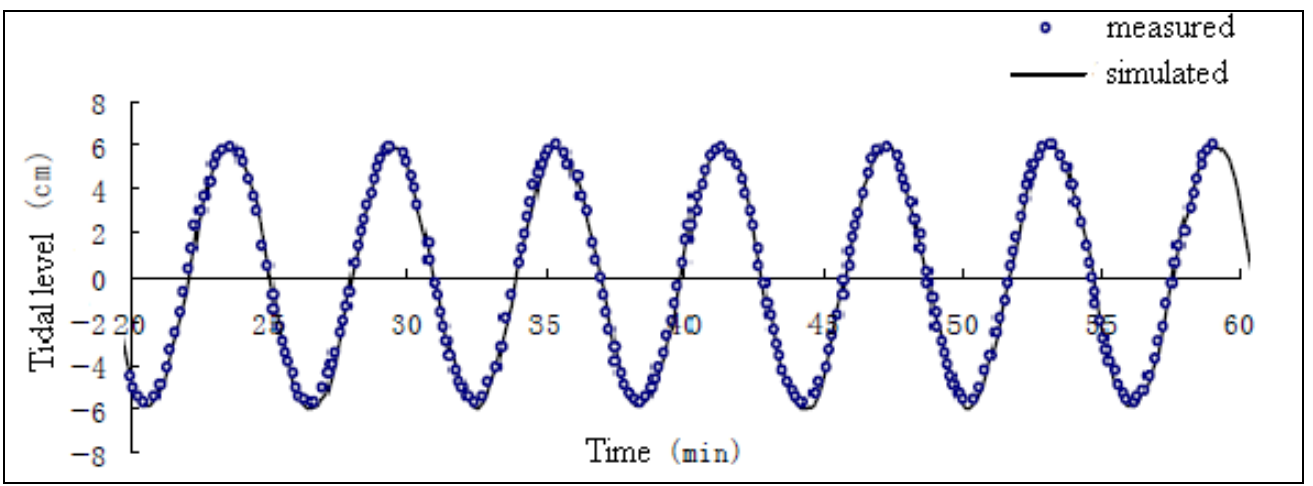

Figure 3. Verification of tidal level at point B

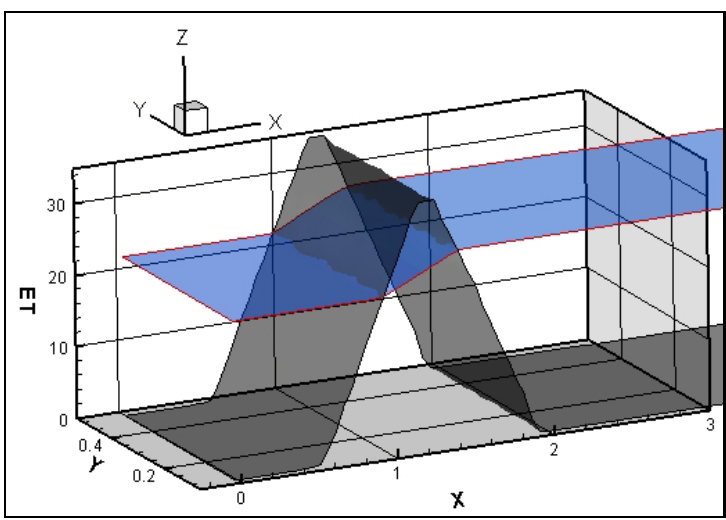

(a) Time $=0$ Tide period

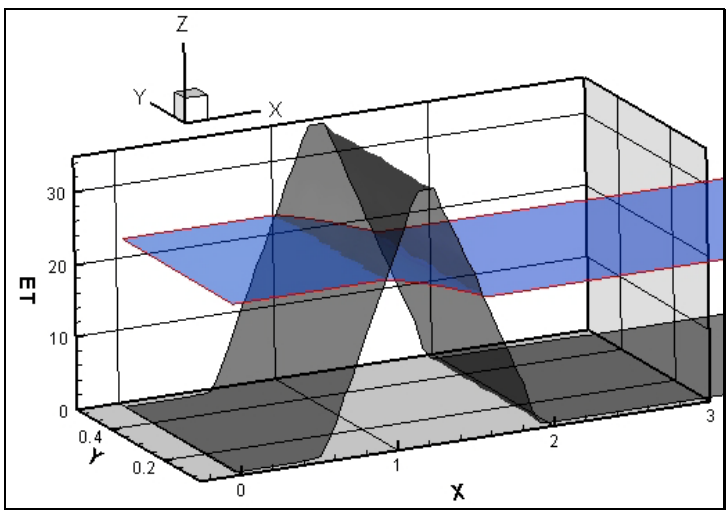

(c) Time $=0.3$ Tide period

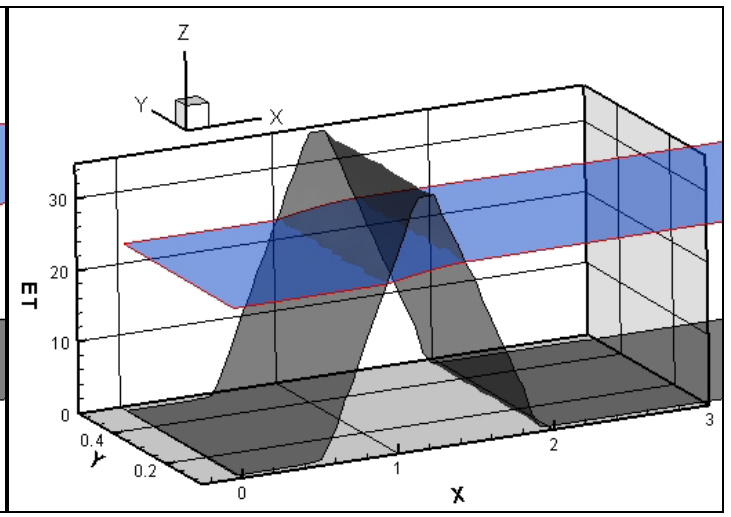

(b) Time $=0.2$ Tide period

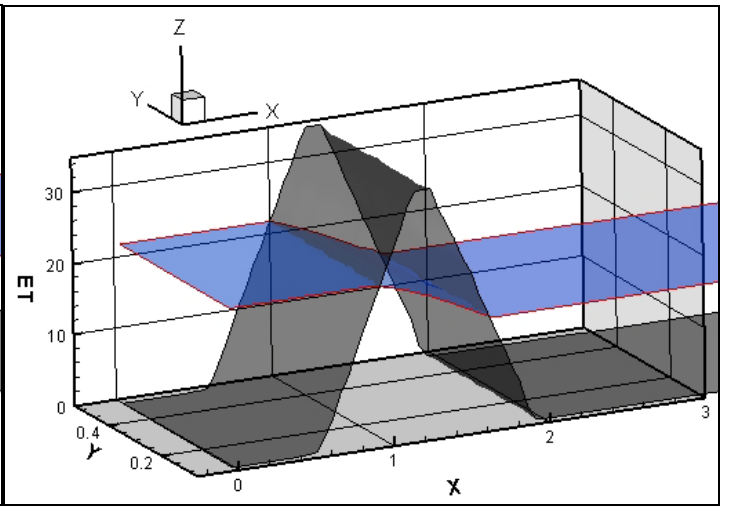

(d) Time $=0.5$ Tide period

Figure 4. Snapshots of the water surface fluctuation 


\section{Discussion}

Further more, detailed analysis was focused on the water hydrodynamic characters in the enclosed lagoon caused by the tidal movement.

At initial stage, the level in lagoon was $6 \mathrm{~cm}$ relative to mean water level and the water surface was above that in open sea, shown in Fig.2. Because of the permeability of sand beach, the water lever reduced quickly. After about one tide period, the water surface began to fluctuate. But because of the porosity friction in sand beach, the wave amplitude in the lagoon was much smaller than that in open sea, and there was a significant phase difference of about 90 degrees between the two water body on two sides of the sand beach. In order to find the relationship between the oscillation and hydrogeology of sand beach, several numerical experiments had been carried with different porosity $n_{e}$ and permeability coefficient $K$ (hydraulic conductivity). Simulated results revealed two main characteristics. Firstly, when the porosity coefficient was increased, the water storage capacity of sand beach would be strengthened which leaded to the reduction of wave oscillation and the phase lag in lagoon. The larger porosity was, the more quickly high water level dropped and low water level elevated, shown in Fig.5; Secondly, when the permeability of sand beach was increased, water moving speed in sand bank was faster, and the wave amplitude in lagoon would be larger, and the phase lag would be weakened. The larger permeability was, the more symmetrical the water surface fluctuation was, shown in Fig.6. The effect of increase on porosity is adverse to that on permeability because of their inverse relationship.

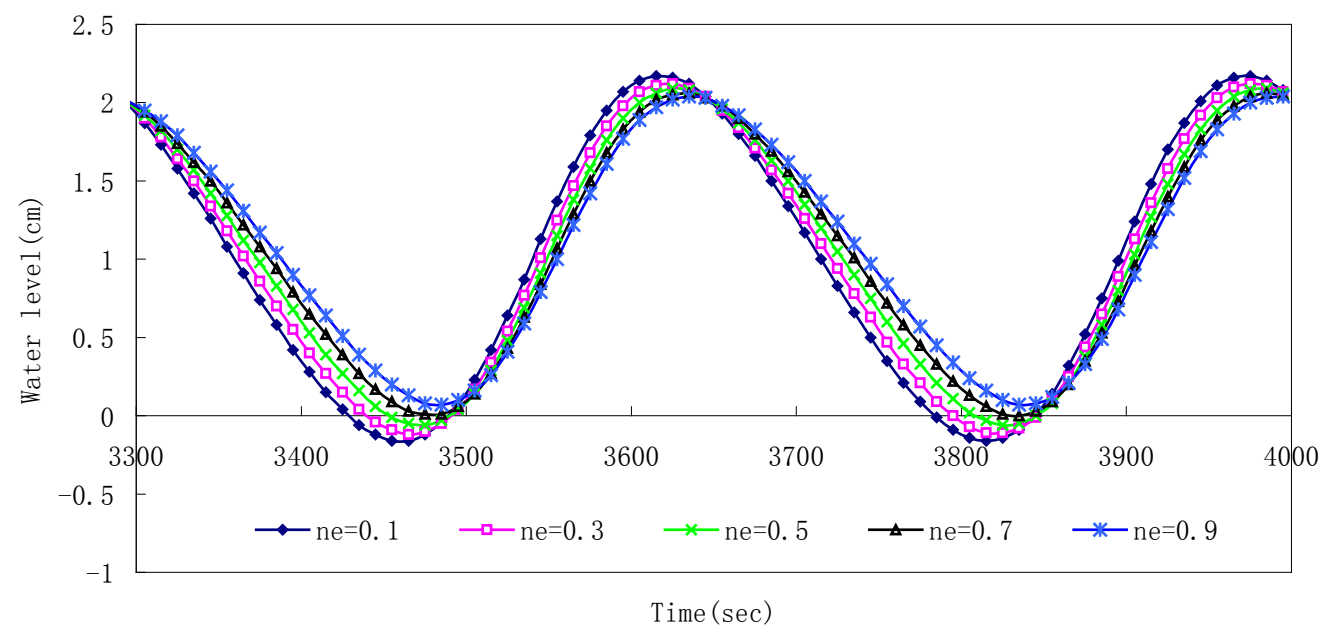

Figure 5. Water level in lagoon with different sand beach porosity (when $K=1 \mathrm{~cm} / \mathrm{s}$ ) 


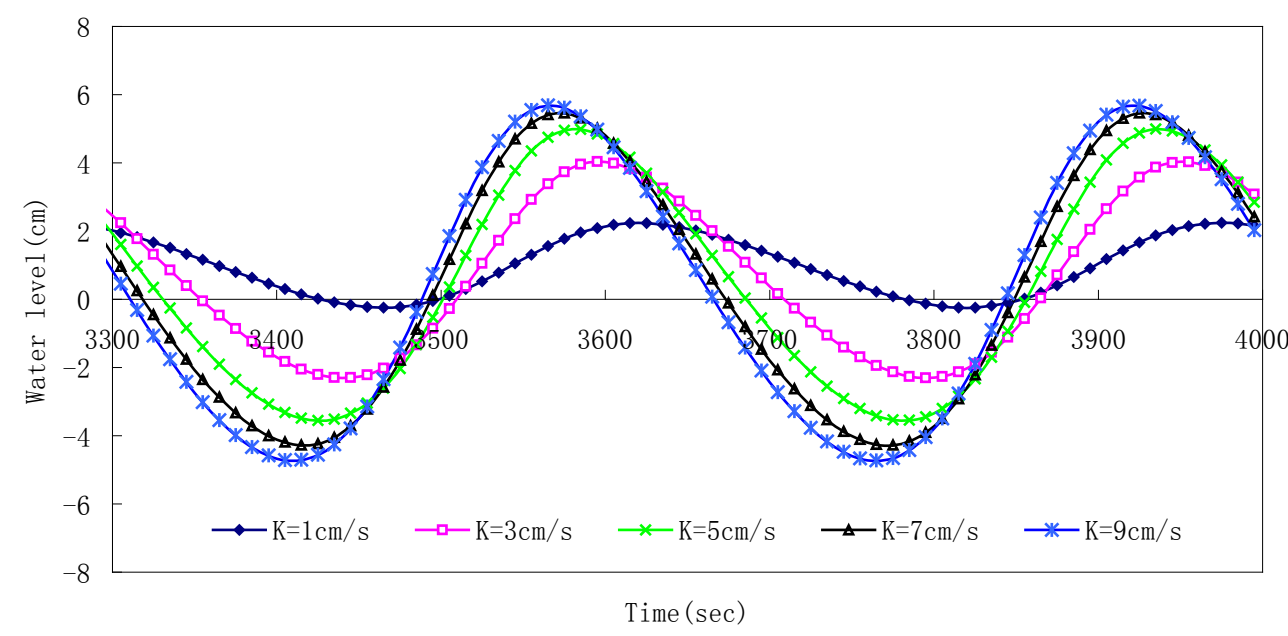

Figure 6. Water level in lagoon with different sand beach permeability (when $n_{e}=0.3$ )

Comparison of measured water level between point A and B showed that the mean water level in lagoon was higher than that in the open sea, which was caused by the groundwater over-height in sand beach. By using numerical simulation, it was shown that with the increase of porosity ,the mean water level in lagoon would increase, shown in Fig.7.In contrary, with the increase of permeability, the mean water level in lagoon would reduce, shown in Fig.8.

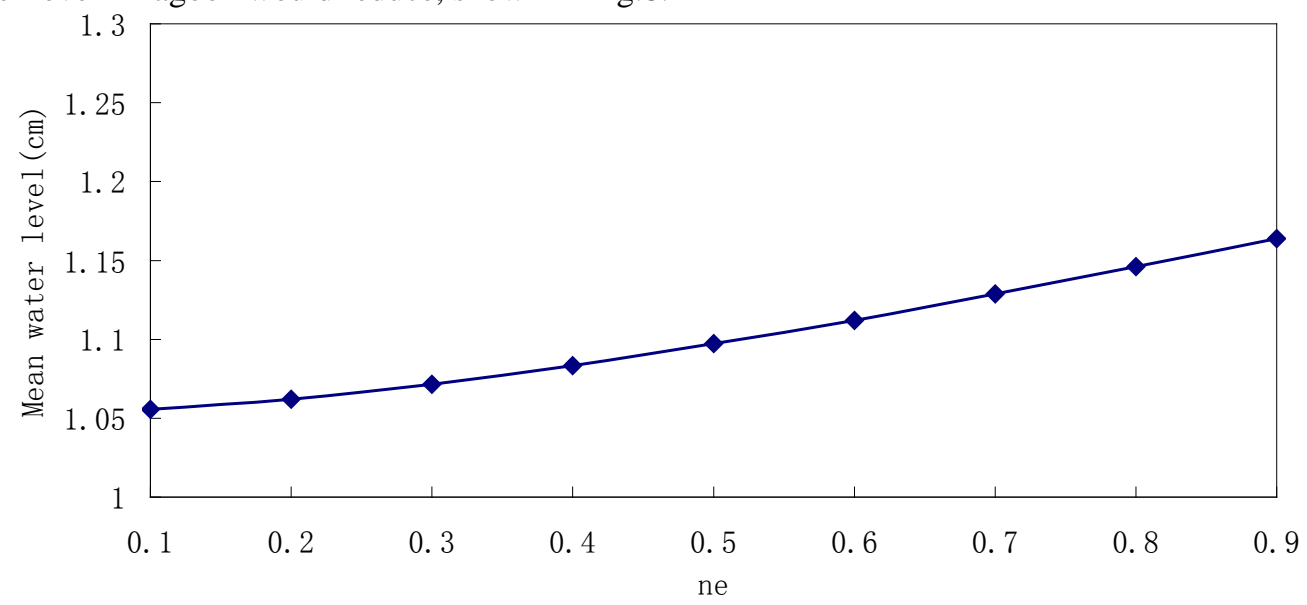

Figure 7. Influence of porosity on mean water level in lagoon $(K=1 \mathrm{~cm} / \mathrm{s})$

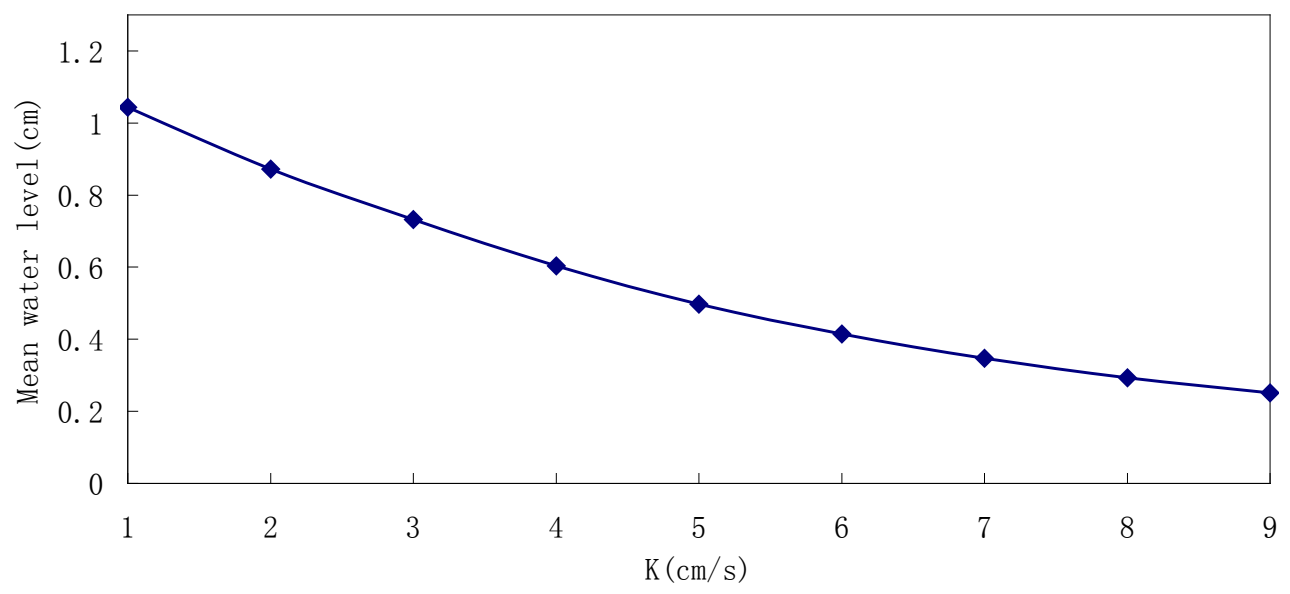

Figure 8. Influence of permeability on mean water level in lagoon $\left(n_{e}=0.3\right.$ ) 
The water fluctuation in lagoon confirmed the existence of water exchange between lagoon and open sea. In other words, it would drive the pollution to move from each other which can explain many environmental problems. Further emphasis was the study on water flux per unit width and water lever on both sides of the sand beach, so four cross sections were placed along sand beach named $\mathrm{A}(x=50 \mathrm{~cm}), \mathrm{B}(x=120 \mathrm{~cm}), \mathrm{C}(x=150 \mathrm{~cm})$ and $\mathrm{D}(x=200 \mathrm{~cm})$ respectively shown in Fig.9. Firstly the tidal levels in $\mathrm{C}$ and $\mathrm{D}$ point were compared. Section $\mathrm{C}$ was near the beach face, so it was influenced by the moving boundary. In ebb when tidal level was above the beach, water level in the two positions dropped down synchronously and equivalently, where surface water and subsurface water coexisted. When the tidal level was low than the beach face, there was only subsurface water movement, and the two water level procedure began to separate. The level dropping speed in section C was slower than that in section $\mathrm{D}$. When the tidal level reached the lowest point in section $\mathrm{D}$, the level in section C had not reached its lowest point and the final end time was later than that in open sea, shown in Fig.10. At initial stages of flood time, although the water level in sand beach was higher than that in open sea, the water level still moves up slowly, which meant that there was water moving from lagoon to open sea which promoted the water level up. So the further study on flux in section B was carried on to reveal the special water exchange procedure.

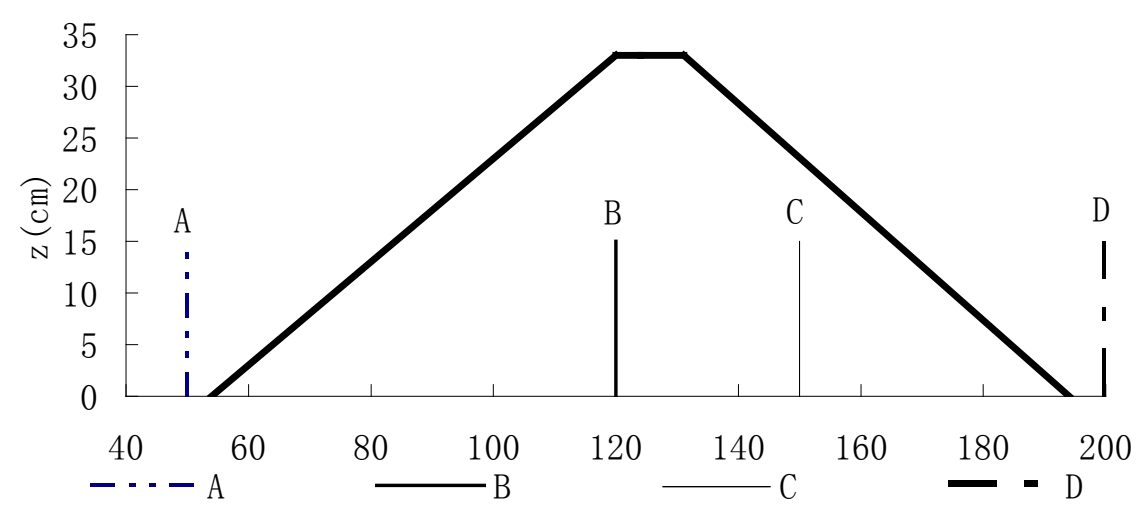

Figure 9. Arrangement of cross section

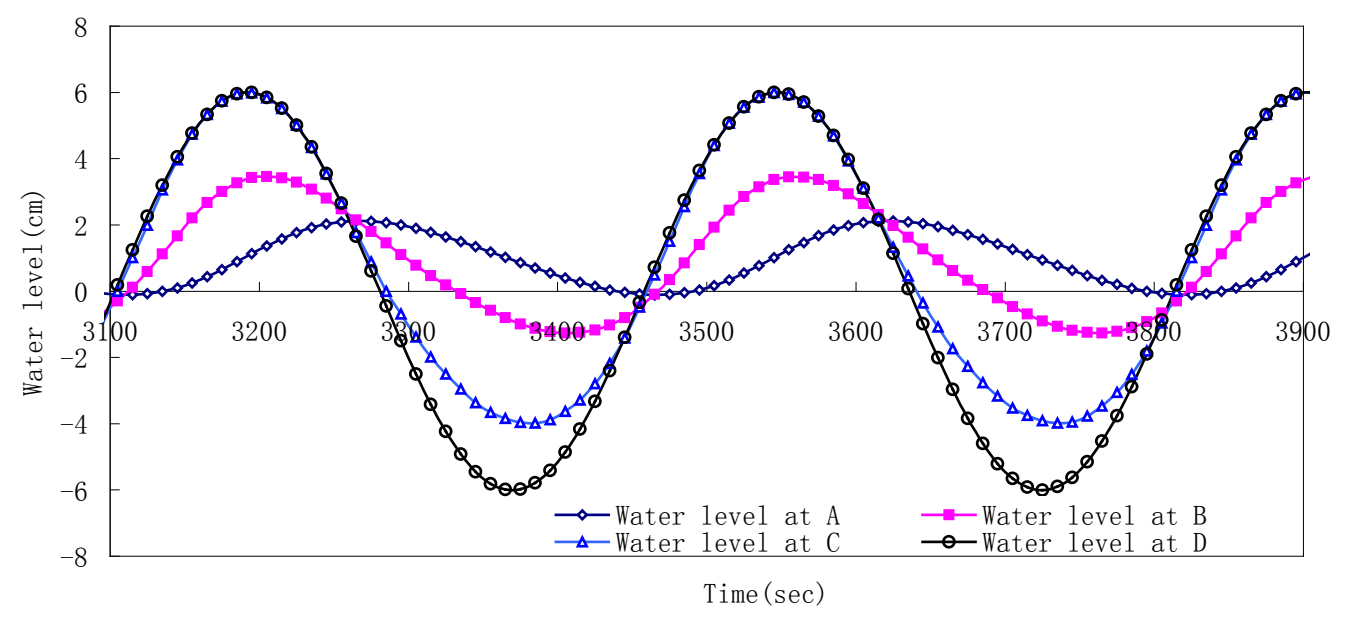

Figure 10. Water level fluctuations with time 
It was defined that the flux was positive when the flow was directed towards the open sea and the flux was negative when the flow was directed away from the open sea. On one hand when the tidal level was the lowest in open sea, the positive flow velocity in sand beach reached its maximum, on the other hand when the tidal level was at the highest, the negative flow velocity in sand beach reached its minimum. Through comparing the maximum value of velocity in two different direction , it was clear that the peak value of positive flux was lower than that of negative flux, and the time of water moving from lagoon to open sea was longer than the reverse procedure. So it obeyed mass conservation law.

Further more, in the early flood period the flow flux in sand beach was still positive, which explained the mentioned phenomena that although the water level in sand beach was higher than the open sea, the water table was still elevated. Through comparing the procedure of flux and water level with tidal period, it was evident that water moves from lagoon to open sea in the initial stage of flood and later stage of ebb, while the reverse procedure happened in the later stage of flood and initial stage of ebb. In addition, during the flood time, the time of water moving from lagoon to open sea was longer than that in ebb time. While in the ebb time, the time of water moving from lagoon to open sea was close to the reverse procedure, shown in Fig.11.

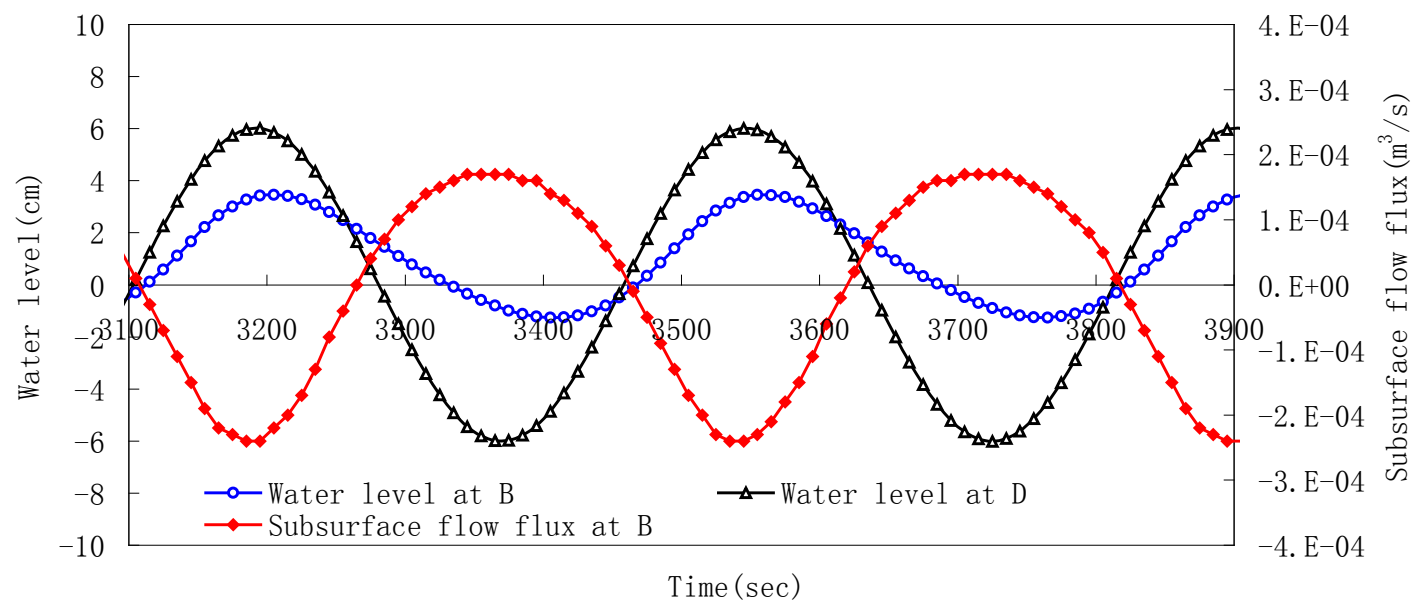

Figure 11. flow flux and water level with time

\section{Conclusions}

By using integrated model to simulate water fluctuation in enclosed lagoon, the hydrodynamic and transport feature were summarized as follows:

(1) With proper sand porosity and permeability, in the coastal enclosed lagoon there exists the water fluctuation induced by tidal movement. Because of the over-height in sand beach, the mean water level in lagoon is higher than that in open sea.

(2) Because of the porosity friction in sand beach, the wave amplitude in the lagoon was much smaller than that in open sea, and there was a significant phase difference.

(3) With the increase of permeability of sandbar, the relationship between enclosed lagoon and open sea is tightened, in which the water fluctuation amplitude becomes larger and the phase lag is weakened. On the contrary, with the increase of porosity, the water fluctuation amplitude is smaller and the phase lag becomes more evident.

(4) There is periodical water exchange between lagoon and open sea. Because the mean sea level in lagoon is higher than that in open sea, the time of water moving from lagoon to open sea is longer than the reverse procedure and the peak value of water flux in the later procedure is larger than the former. Experiment shows that the water moving from lagoon to open sea usually happens in the initial stage of flood and later stage of ebb, while the reverse procedure happens in the later stage of flood and initial stage of ebb.

\section{ACKNOWLEDGEMENTS}

This study was supported by the National Natural Science Foundation of China (51009059) and Fundamental Research Funds for the Central Universities (2010B02914) . 


\section{REFERENCES}

Casulli, V., Stelling, G. S.,1998. Numerical simulation of three-dimensional quasi-hydrostatic, free surface flows, Journal of Hydraulic Engineering, 124, 678-686.

Ebrahimi, K., Falconer, R.A., Lin, B., 2007. Flow and solute fluxes in integrated wetland and coastal systems, Environmental Modeling \& Software ,22,1337 - 1348.

Huang, C.J., Chang, H. H., 2003.Structural permeability effect effects on the interaction of a solitary wave and a submerged breakwater, Coastal engineering,49, 1-24.

Kong, J., Xin, P.,Song, Z.Y., Li, L.,2010. A new model for coupling surface and subsurface water flows: with an application to a lagoon, Journal of Hydrology, 390,116-120.

Leticia,B.R.,Pablo,A.C.,Carlos,A.V.,2008. Full conservative coupling of HEC-RAS with MODFLOW to simulate stream-aquifer interactions in a drainage basin , Journal of Hydrology, 353(1-2), 129-142.

Liang, D., Falconer, R.A., Lin, B., 2007. Coupling surface and subsurface flows in a depth averaged flood wave model, Journal of Hydrology, 337, 147-158.

Mcdougal,W.G.,1993. State of the art practice in coastal engineering, Lecture Notes, National Cheng Kung University, Taiwan, 10.25-10.28.

Panday,S.,Huyakorn,P.S.,2004.A full coupled physically-based spatially distributed model for evaluating surface/subsurface flow, Advance in Water Resource, 27(4),361-382.

Walters, R.A., Emmanuel,H., Pietrzak J. , Le Roux D.Y.,2009. Comparison of unstructured, staggered grid methods for the shallow water equations, Ocean Modelling,28,106-117.

Yuan, D., Lin, B., Falconer, R.A., 2008. Simulating moving boundary using a linked groundwater and surface water flow model ,Journal of Hydrology, 349, 524-535.

Zhang, Y., Baptista, A.M., Myers, E.P., 2004. A cross-scale model for 3D baroclinic circulation in estuary-plume-shelf systems: I. Formulation and skill assessment, Continental Shelf Research, 24, 2187-2214. 